\title{
Assessment of L/D Ratio of Eco Fibre - Bamboo as a Reinforcement Material in Concrete
}

\author{
Kavitha.s ${ }^{\# 1}$, T.Felix kala ${ }^{* 2}$

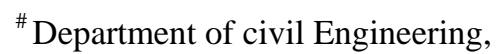 \\ Dr. M.G.R Educational and Research Institute University, Chennai, India \\ ${ }^{1}$ sajjalakavitha@gmail.com \\ * Department of Civil Engineering, \\ Dr. M.G.R Educational and Research Institute University, Chennai, India \\ ${ }^{2}$ kalastruct@yahoo.co.in
}

\begin{abstract}
Fibres are commonly used in concrete to control the cracks, shrinkage and to improve the strength and performance of the concrete. Generally various types of fibres are used like natural and artificial fibres in the concrete mix to produce the expected strength and crack resistance. an attempt is made to innovate a natural, eco friendly fibre which is available to the common man. In this paper, tests are carryout on bamboo fibre reinforced concrete to evaluate aspect ratio (1/d) of bamboo fibres. Different ages of bamboo is collected, the extraction of fibres is done by mechanical method. Once the bamboo fibres are extracted the various lengths and diameters are selected and SEM analysis is carried out to find out the microstructure of bamboo fibres to know the failure analysis .these selected bamboo fibres add at the fixed rate of $0.1 \%$ to $1.5 \%(0.5,0.75,1,1.25,1.5)$ by the cement weight to the concrete mix. Then the samples of cubes, beams and cylinders are casted from the concrete mix and curing will be done for required period. Experimental investigations are carried out using most commonly used tests in laboratory, which includes concrete workability test, compressive test, split tensile test, and test for flexure from the various test results the aspect ratio ( $1 / \mathrm{d}$ ratio) and also the effectiveness of bamboo fibres usage in concrete has been evaluated.
\end{abstract}

Keyword- Bamboo fibre, Aspect ratio, Structure, Extraction, SEM analysis.

\section{INTRODUCTION}

Egyptians has developed this concept of using the fibres in the concrete mix as a reinforcing material. Before they used to mix the straw and hairs of animals in the concrete as a material of reinforcement for fixing of bricks in walls. The production of fibres is also in less percentage and to give potentiality to this by providing a land to improve this is very necessary. So that there is a similar way is to extracting the fibre is the major problem. To that problem the only solution is these bamboo fibres. This is bamboo is not grass or not a wood, but it is having the characteristics of both the grass and wood. In the recent years the concept of fibre reinforcement concrete is a great development to enhance effectiveness and grater performance related results in concrete it is much necessary to produce the high strength, performance and durability with desirable aspect ratio from which the effectiveness and the good results of performance are to developed in the concrete. The main reason of using the natural fibres to providing the greater strength and good resistance capacity to structures and to achieve the greater performances from it by making the structures rigid. The fibres are mixed randomly in the concrete mix with the calculated percentages of contents of the fibre reinforced concrete. The characteristics of the fibres and materials should effects on the results of fibre reinforced concrete. Whereas results are depends on the types of fibres used, shape of fibres, percentage content mix in concrete and the method of mixing fibres in concrete, the size of the aggregate, shape and texture of the aggregate. The fibres are the pieces of small size materials used for reinforcement which may be available naturally or manufactured artificially. The fibres may be flat in shape, triangle or may be in circular shape. The property of the fibre is often defined by the parameter which is known as "Aspect Ratio". The ratio of fibre length to the fibre diameter is called as aspect ratio. The length of the fibre is decided by the multiplying the diameter to the aspect ratio. This length will be influences on the strength of fibres which may in flexure, compression and may be tension.

\section{Materials}

The materials used in the present experimental programme are as follows:

A. Cement (53-grade OPC): The cement consists of preliminary percentage of silicates and some percentage of lime aluminates. On this experiment 53-grade ordinary Portland cement was used for the all mixes. The cement used was contemporary with none lumps.

B. Coarse aggregates: Locally available crushed granite aggregate which are passing from the IS sieve size of $20 \mathrm{~mm}$ and which are retaining in the IS sieve size of $12.5 \mathrm{~mm}$ are to be generally used for the construction. 
The coarse aggregates used were confirming to IS 383:1970. The highest size and grading of the aggregates depends on the special applications.

C. Fine aggregates: Locally available high quality sand gathered from river bed, that should be pass from IS sieve $4.75 \mathrm{~mm}$ and the same will be for all of the mixes of concrete. The fine aggregate which is having fineness modulus 2.81 is used were confirming to zone II according to IS code.

D. Bamboo fibres: Bamboo fibres are the naturally available fibres which are available locally. These are different age which varies in the strength when they are used in the concrete mix as a reinforcing material. The bamboos are having a good length, which can give good characteristics when it has been used as a reinforcing material. In structure these are hollow long structures which consist of rings. In between the two rings they will be having a structure called as Internodes. From these internodes the branches will be grown. The internal structures of the bamboo will be consisting of conducting tissues those are parenchyma cells and the sclerenchyma cells. These parenchyma cells consist of vascular bundles. These vascular bundles will be having a major part in the strength. The strength of the bamboo fibres has been decided by the number of vascular bundles present in it. Higher the vascular bundles higher the strength of fibres. The bamboos of different ages are shown in following figure.

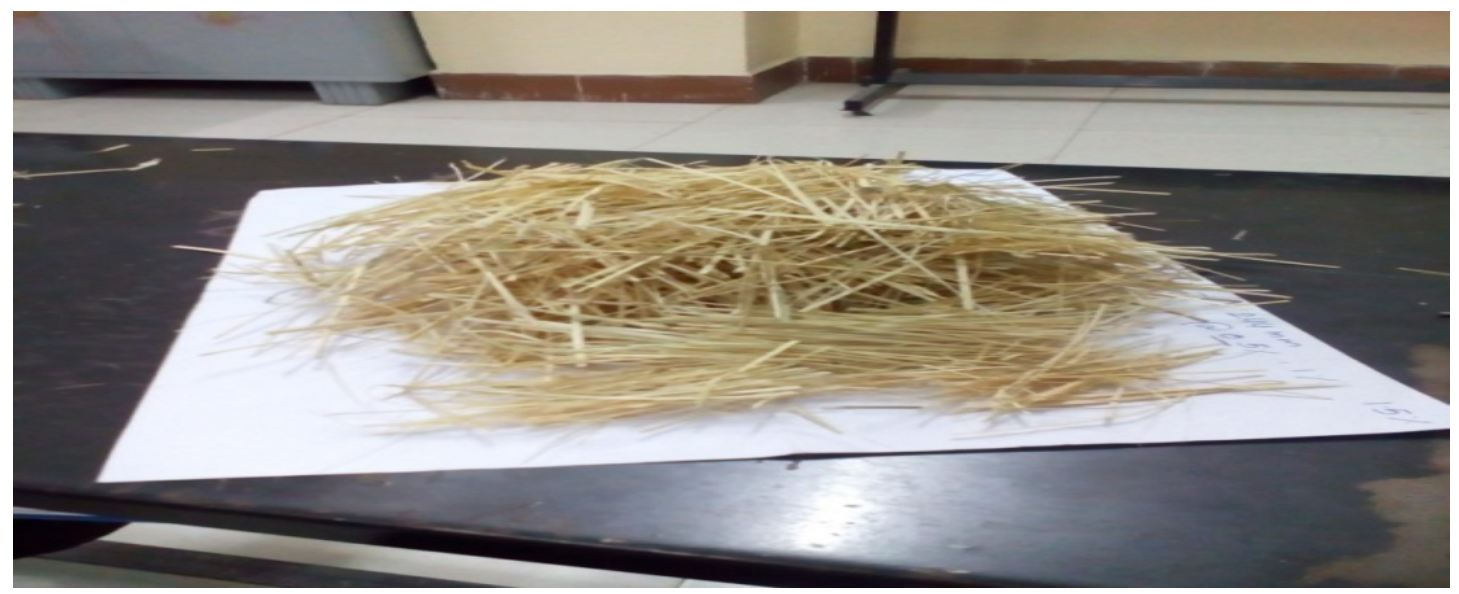

Fig. 1. Natural bamboo fibre

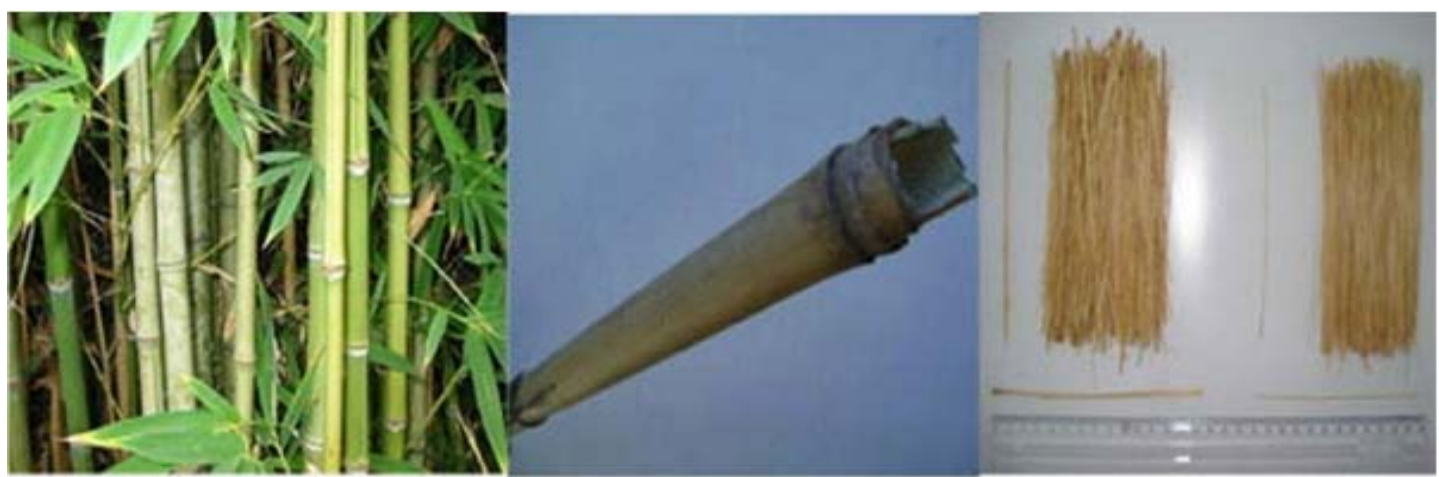

Fig. 2. Processing of bamboo fibres

Generally there is less ideas and minimum knowledge about the these extracting of bamboo fibre and also there is only less number of studies and investigations are carried out. The commonly used method in extracting fibre is,

1) Extracting by mechanical method: In this method the young bamboo of age two to eight months is selected and it is cleaved vertically into number of strips. Those strips are taken into roller to lose the strips and they will drive under the roller. After rolling that strips are to be boiled for ten hours at $900 \mathrm{C}$. Later these strips will dry and the small pieces of fibres are to be extracted. 


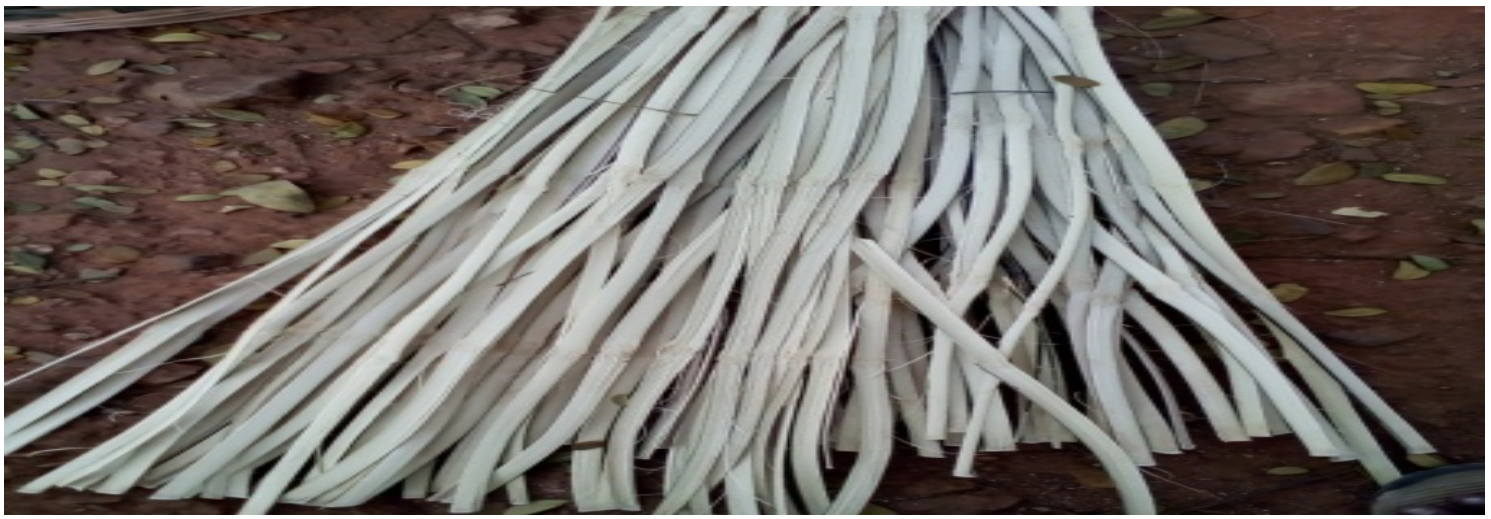

Fig. 3. Cleaved young age bamboo strips

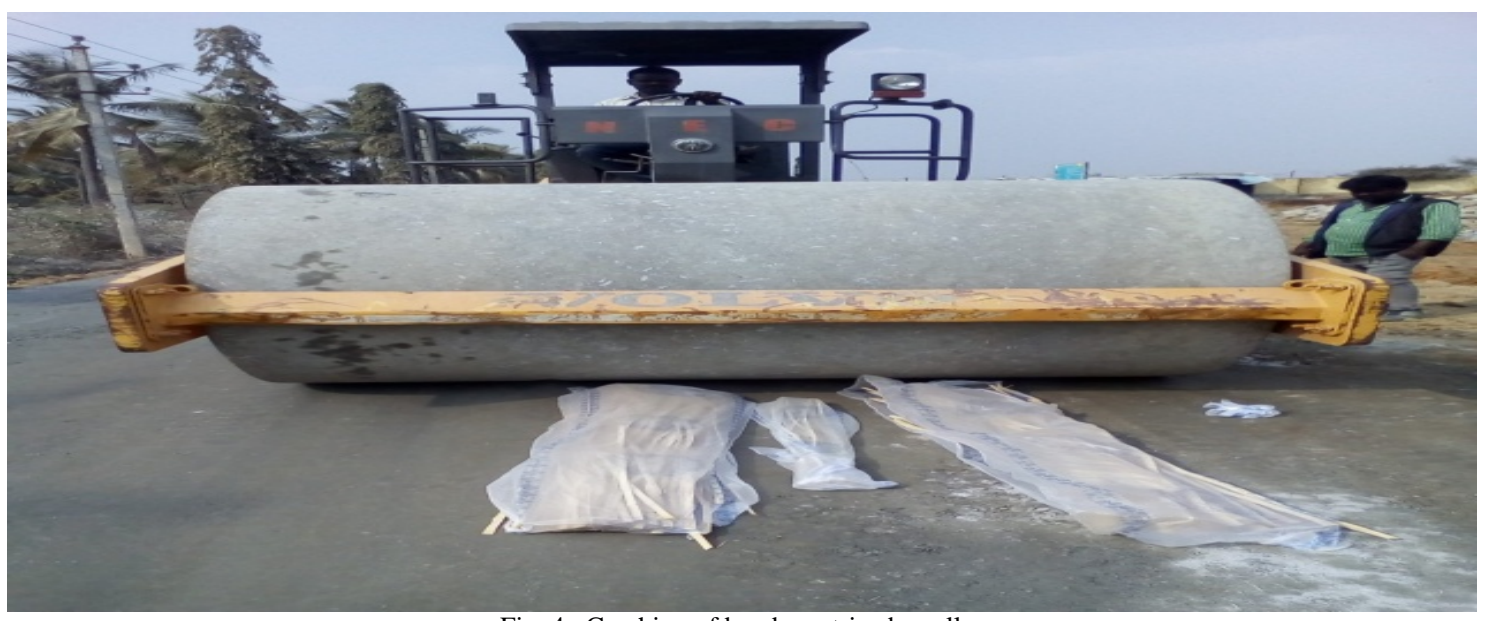

Fig. 4. Crushing of bamboo strips by roller

2) Sem analysis test on bamboo fibre:

Scanning electron microscopy test has been conducted to examine the micro structure of bamboo fibre and failure analysis as well as the diameter of bamboo fibre.

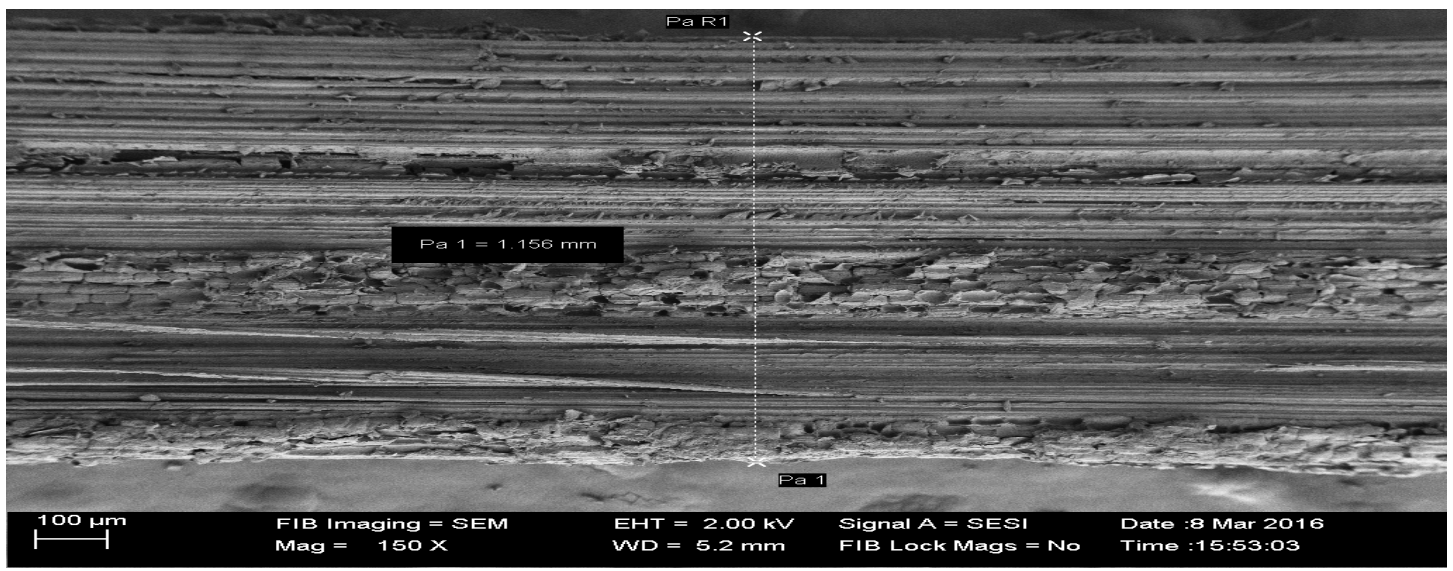

Fig. 5. Scanning Electron Microscoping image of bamboo fibre of diameter 1.156mm

\section{III.RESULTS AND DISCUSSIONS}

A. Compressive strength: It is noted from table I, that the 28 days compressive strength for bamboo fibres for M30 grade bamboo fibre reinforced concrete is 41 Mpa which is obtained at $1 \%$ of fibres of diameter $1.156 \mathrm{~mm}$ with an aspect ratio (l/d) of 40 mixed with concrete. 
TABLE I. Results of 28 days compressive strength of BFRC D1 (diameter 1.244mm)

\begin{tabular}{|c|c|c|c|c|}
\hline \multirow[t]{2}{*}{ No } & \multirow[t]{2}{*}{ Description } & \multicolumn{3}{|c|}{28 days Compressive strength(N/mm2) } \\
\hline & & (1/d) 30 & (l/d) 40 & (1/d) 50 \\
\hline 1 & $0 \%$ & 30.1 & 32.8 & 30.6 \\
\hline 2 & $0.5 \%$ fibre & 30.8 & 33.7 & 31.1 \\
\hline 3 & $0.75 \%$ fibre & 32.3 & 36.8 & 34.2 \\
\hline 4 & $1 \%$ fibre & 33.6 & 41 & 35.1 \\
\hline 5 & $1.25 \%$ fibre & 34.9 & 38.9 & 38.1 \\
\hline
\end{tabular}

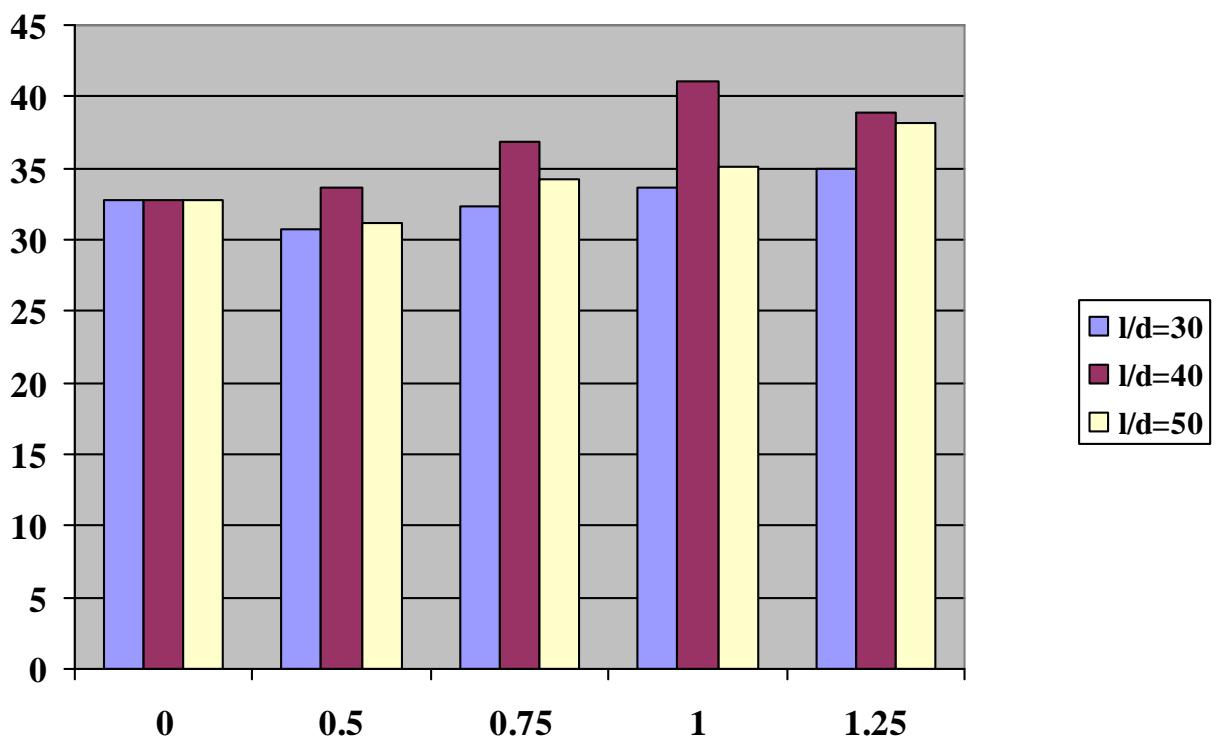

Fig.6. 28 days Compressive strength of BFRC [Diameter=1.156mm]

B. Split tensile Strength: It is noted from table II, that the 28 days tensile strength for bamboo of M30 grade bamboo fibre reinforced concrete is $4.8 \mathrm{Mpa}$ which is obtained at $1 \%$ of fibre, diameter of $1.156 \mathrm{~mm}$ with an aspect ratio (l/d) of 40 mixed with concrete.

TABLE II. Results of 28 days split tensile strength of BFRC D1 (diameter 1.156mm)

\begin{tabular}{|l|l|l|l|l|}
\hline \multirow{2}{*}{ No } & \multirow{2}{*}{ Description } & \multicolumn{3}{|c|}{ 28 days split tensile strength(N/mm2) } \\
\cline { 3 - 5 } & & $\mathbf{( I / d )} \mathbf{3 0}$ & $\mathbf{( l / d )} \mathbf{4 0}$ & \multicolumn{1}{|c|}{$(\mathbf{l} / \mathbf{d}) \mathbf{5 0}$} \\
\hline 1 & $0 \%$ & 2.68 & 2.68 & 2.68 \\
\hline 2 & $0.5 \%$ fibre & 2.98 & 3.1 & 3. \\
\hline 3 & 0.75 \% fibre & 3.7 & 4.1 & 3.9 \\
\hline 4 & $1 \%$ fibre & 3.81 & 4.8 & 4.2 \\
\hline 5 & $1.25 \%$ fibre & 3.92 & 4.3 & 3.9 \\
\hline
\end{tabular}




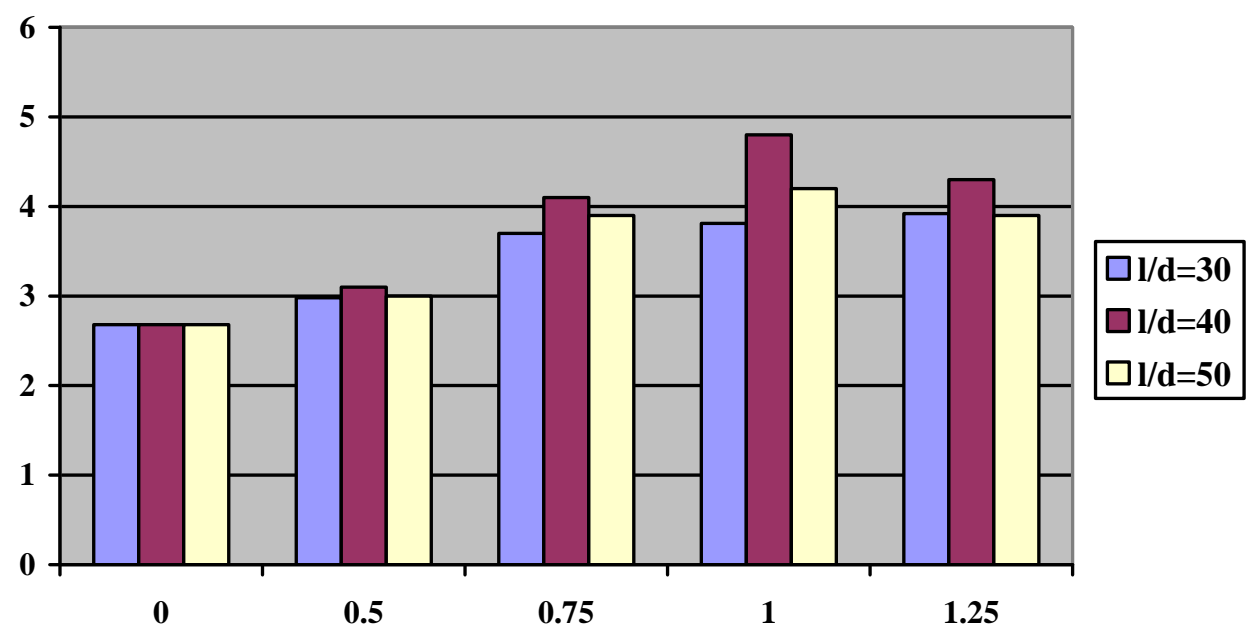

Fig.7. 28 days split tensile strength of BFRC [Diameter=1.156mm]

C. Flexural strength: It is noted from table III, that the 28 days flexural strength for bamboo fibre based on M30 grade bamboo fibre reinforced concrete is 8.5 Mpa which is obtained at $1 \%$ of fibre mixed with concrete of diameters of fibre is of $1.156 \mathrm{~mm}$ with an aspect ratio (l/d) of 40 .

TABLE III. Results of 28 days Flexural strength for BFRC $D=1.156 \mathrm{~mm}$

\begin{tabular}{|l|l|l|l|l|}
\hline \multirow{2}{*}{ No } & \multirow{2}{*}{ Description } & \multicolumn{4}{|c|}{ 28 days flexural strength(N/mm2) } \\
\cline { 3 - 5 } & & $\mathbf{( l / d )} \mathbf{3 0}$ & $\mathbf{( I / d )} \mathbf{4 0}$ & $\mathbf{( l / d ) ~ 5 0}$ \\
\hline 1 & $0 \%$ fibre & 4.68 & 4.68 & 4.68 \\
\hline 2 & $0.5 \%$ fibre & 5.1 & 6.8 & 7.1 \\
\hline 3 & $0.75 \%$ fibre & 6.23 & 7.02 & 7.6 \\
\hline 4 & $1 \%$ fibre & 6.9 & 7.25 & 7.9 \\
\hline 5 & $1.25 \%$ fibre & 7.1 & 7.5 & 8.5 \\
\hline
\end{tabular}

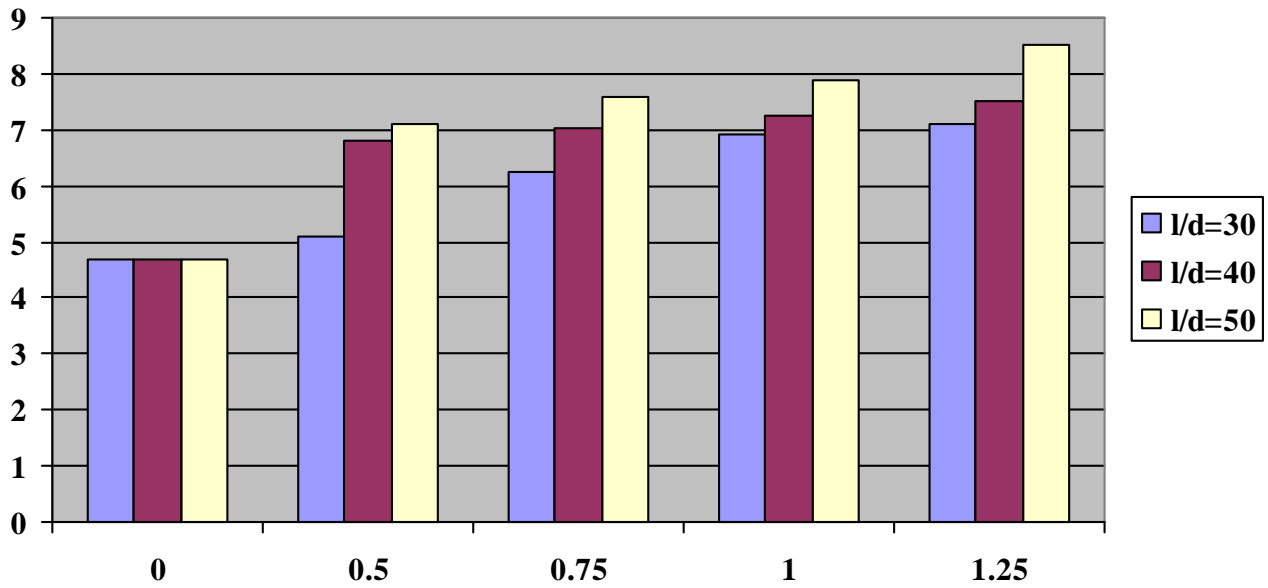

Fig.8. 28 days Flexural strength of BFRC [Diameter1.156mm] 


\section{ConCLusion}

An innovative natural, eco friendly fibre is introduced to the field of concrete to enhance the tensile and torsion properties. Bamboo fibre is one which is of low cost and to produce high strength concrete. Keeping focus on substitution for natural plants fibre, as they having the advantages such as very less cost, density is lower, friendly with environment. The fibre reinforced concrete with different fibre ratios has given tremendous results compared to normal concrete. Greater compressive strength has been obtained when $1 \%$ of fibre mixed with concrete of aspect ratio (l/d) 40 when compared to $0 \%, 5 \%, .75 \%$, and $1.25 \%$.The maximum Split tensile strength is obtained with $1 \%$ of fibre with aspect ratio of (l/d) 40 when compared to $0 \%, 5 \%, .75 \%$, and $1.25 \%$.The maximum flexural strength is obtained withaddition of fibres.From the experimental investigations aspect ratio (l/d) 40 has given the maximum results with $1 \%$ of fiber content.

\section{ACKNOWLEDGMENT}

The Authors are thankful to professor and head, dean, president, Dept of civil engineering, Dr.M.G.R Educational and research institute university, Chennai.

\section{REFERENCES}

[1] Nguyen tien phog,toru fujii,bui chuong,kazuya okubo,"study on how effectively extract bamboo fibres from raw bamboo and waste water treatment”journal of materials science research"vol 1,pp145-150,jan 2012.

[2] p.zakikhani,R.zahari,M.T.H.Sultan,D.L.Majid”bamboo fibre extraction and its reinforced polymer composer material”international journal of chemical,molecular,nuclear,materials and metallurgical engineering,vol 8,no.4,2014.

[3] Masakazu terai \&koichi minami,Reasearch and development on bamboo reinforced concrete structure,15WCEE2012.

[4] Kavitha.s, dr.t.felix kala, Study on structure and extraction of bamboo fiber as strength enhancer in concrete, IJRET, e-ISSN : 23191163, pISSN:2321-7308, Volume:03, Issue: 01, January 2016.

[5] Kavitha.s,dr.t.felix kala,effect of bamboo fibres in fresh and hardened properties of self compacting concrete ,Indian journal of science and trechnology,ISSN-0974-6846,ISSN(Online)-0974-5645,volume (9)issue31,august 2016.

[6] Kavitha.s,dr.t.felix kala, Evaluation of Strength Behavior of Self-Compacting Concrete using Alccofine and GGBS as Partial Replacement of Cement, Indian journal of science and trechnology, ISSN-0974-6846, ISSN(Online)-0974-5645, volume (9)issue22,august 2016.

[7] Kavitha.s,dr.t.felix kala,bamboo fibre analysis by scanning electron microscope study, international journal of civil engineering and technology,IJCIET,volume 7,issue 4,july-august 2016,pp234-241.

\section{AUTHOR PROFILE}

Author1 kavitha.s, currently pursuing Ph.D from Dr.M.G.R Educational and research institute university.

Author2 Dr.T.Felix kala, currently working as professor and HOD,Department of civil engineering, Dr.M.G.R Educational and research institute university. 